\title{
RESEARCH
}

\section{MINDIN secretion by prostate tumors induces premetastatic changes in bone via $\beta$-catenin}

\author{
Juan A Ardura1,2,*, Luis Álvarez-Carrión1,*, Irene Gutiérrez-Rojas', Peter A Friedman³, Arancha R Gortázar1,2 and \\ Verónica Alonso (iD),2 \\ 'Bone Physiopathology Laboratory, Applied Molecular Medicine Institute (IMMA), Universidad San Pablo-CEU, CEU Universities, Campus Monteprincipe, \\ Madrid, Spain \\ 2Departamento de Ciencias Médicas Básicas, Facultad de Medicina, Universidad San Pablo-CEU, CEU Universities, Campus Monteprincipe, Madrid, Spain \\ ${ }^{3}$ Laboratory for G Protein-Coupled Receptor Biology, Department of Pharmacology \& Chemical Biology, University of Pittsburgh School of Medicine, \\ Pittsburgh, Pennsylvania, USA
}

Correspondence should be addressed to V Alonso: veronica.alonsorodriguez@ceu.es

*(J A Ardura and L Álvarez-Carrión contributed equally to this work)

\begin{abstract}
Bone metastases are common in advanced prostate cancer patients, but mechanisms by which specific pro-metastatic skeletal niches are formed before tumor cell homing are unclear. We aimed to analyze the effects of proteins secreted by primary prostate tumors on the bone microenvironment before the settlement and propagation of metastases. Here, using an in vivo pre-metastatic prostate cancer model based on the implantation of prostate adenocarcinoma TRAMP-C1 cells in immunocompetent C57BL/6 mice, we identify MINDIN as a prostate tumor secreted protein that induces bone microstructural and bone remodeling gene expression changes before tumor cell homing. Associated with these changes, increased tumor cell adhesion to the endosteum ex vivo and to osteoblasts in vitro was observed. Furthermore, MINDIN promoted osteoblast proliferation and mineralization and monocyte expression of osteoclast markers. $\beta$-catenin signaling pathway revealed to mediate MINDIN actions on osteoblast gene expression but failed to affect MINDIN-induced adhesion to prostate tumor cells or monocyte differentiation to osteoclasts. Our study evidences that MINDIN secretion by primary prostate tumors creates a favorable bone environment for tumor cell homing before metastatic spread.
\end{abstract}

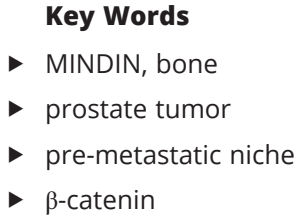

Endocrine-Related Cancer (2020) 27, 441-456

\section{Introduction}

Advanced cancers that progress to tumor metastases are often considered incurable or difficult to treat (Weilbaecher et al. 2011, Logothetis et al. 2018). Bone is the third most frequent site for metastatic disease, with an incidence of $65-80 \%$ in patients suffering from common diagnosed tumors such as those of the prostate, breast, and lung (Mundy 2002, Salamanna et al. 2016). Preventing bone metastasis is a major goal of treatment, and elucidation of the crucial factors contributing to the development of skeletal metastasis is key to improve cancer survival. A series of studies suggest that bone metastatic organotropism, the ability of tumor cells to colonize specifically bone, is due to cancer cell acquisition of osteomimetic features, that is, they express highly restricted markers of bone and adopt behaviors of bone cells. Osteomimicry promotes productive interaction (c) 2020 Society for Endocrinology Published by Bioscientifica Ltd. Printed in Great Britain 
of cancer cells with the skeletal microenvironment, as well as survival advantages and cancer cell growth (Koeneman et al. 1999, Zayzafoon et al. 2004, Gupta \& Massagué 2006, Kingsley et al. 2007, Baniwal et al. 2010, Croucher et al. 2016, Kan et al. 2016). In bone metastasis it is hypothesized that tumor cells home to specific niches such as the endosteal niche, the hematopoietic stem cell niche, and the vascular niche (Ottewell 2016). Primary tumor invasion of these niches in bone is associated with osteoclast and osteoblast activation by tumor cells, resulting in the liberation of growth factors from the bone matrix that can in turn enhance tumor growth. The resulting 'vicious cycle' of bone metastasis changes the normal bone physiology and triggers uncoupled bone remodeling (Roodman 2004, Guise et al. 2006, Akech et al. 2010). In this process, tumor cells produce cytokines and growth factors, which either directly stimulate osteoclast maturation or indirectly promote osteoclast differentiation (Ell \& Kang 2012). Bone matrix resorption by activated osteoclasts releases TGF- $\beta$ and insulin-like growth factor-1 (IGF-1) and promotes the survival and proliferation of cancer cells inducing osteolytic metastatic lesions (Quail \& Joyce 2013). In contrast, other factors such as fibroblast growth factor (FGF), bone morphogenetic proteins (BMPs), and IGFs can also be secreted by tumor cells to stimulate osteoblast differentiation and subsequent uncontrolled bone formation, resulting in osteoblastic lesions (Suva et al. 2011). In the case of prostate cancer, it has been proposed that bone metastases are promoted by both osteolytic and osteoblastic activity (Keller \& Brown 2004).

Although tumor-bone 'vicious cycle' mechanisms at metastatic sites have been described, the primary processes triggering formation of the metastatic niche and the colonization of a predetermined location by tumor cells are largely unknown. In this regard, bone marrow hematopoietic progenitor cells modify metastatic secondary sites, such as lung, before the establishment of the tumor cells (Kaplan et al. 2005). Tumors actively recruit various bone marrow-derived cell types to the tumor microenvironment, where these cells facilitate primary tumor development and metastasis (Polyak \& $\mathrm{Hu} 2008$ ). Other observations reveal a series of sequential events that imply formation of specific regions in the liver with respect to future metastases induced by pancreatic cancer (Costa-Silva et al. 2015). These studies propose pro-metastatic changes in organs where metastases later appear. Such changes involve the formation of premetastatic niches that can be defined as receptive tissue microenvironments undergoing molecular and cellular modifications to form the metastatic-designated sites, in preparation for metastatic tumor cell colonization, thus supporting tumor settlement in distant organs (Kaplan et al. 2005, Peinado et al. 2012, Cox et al. 2015, Liu \& Cao 2016). Nevertheless, pre-metastatic niche formation in bone during primary prostate tumor progression has not been sufficiently studied.

Primary tumor-secreted soluble molecules play critical roles in preparing distant sites for de novo pre-metastatic niche formation, thereby promoting metastasis and even determining metastatic organotropism (Liu \& Cao 2016). MINDIN, a secreted extracellular matrix protein, has been shown to be overexpressed in individuals with prostate tumors that present high risk to progress to metastatic disease compared with patients with low metastatic risk tumors, suggesting that this protein could be used as diagnostic biomarker of prostate cancer (Qian et al. 2012, Lucarelli et al. 2013, Zhu et al. 2017). Moreover, recently our group has described that overexpression of MINDIN in tumors and adenocarcinoma cells correlates with increased osteomimetic gene expression and with the potential of MINDIN-expressing cells to metastasize to bone (Ardura et al. 2019). This protein, also known as spondin-2, belongs to the thrombospondin type 1 repeat (TSR-1)-containing class of molecules (Li et al. 2009). Interestingly, other members of the TSR-1 superfamily that share some structural domains with MINDIN, namely F-spondin and R-spondins (de Lau et al. 2012), have been shown to trigger changes in bone by regulating bone morphogenetic proteins or the Wnt/ $\beta$-catenin signaling pathway (Friedman et al. 2009, Palmer et al. 2014, Zhu et al. 2016). However, no previous reports describe the effects of MINDIN on bone or whether a crosstalk between MINDIN and Wnt/ $\beta$-catenin signaling pathway exists.

Based on these observations, we hypothesized that MINDIN secreted by primary prostate tumors triggers changes in the bone microenviroment, thereby inducing the formation of a pre-metastatic bone niche.

\section{Materials and methods}

\section{Cell culture}

Mouse adenocarcinoma prostate TRAMP-C1 (ATCC: CRL-2730) cells were grown in DMEM supplemented with 5\% FBS and 5\% Nu-serum IV, $0.005 \mathrm{mg} / \mathrm{mL}$ bovine insulin and $10 \mathrm{nM}$ dehydroisoandrosterone. Mouse osteoblastic MC3T3-E1 (ATCC: CRL-2593) and monocytic RAW 264.7 cells (ATCC: TIB-71) were grown in DMEM 
with 10\% fetal bovine serum (FBS) and osteocyte MLO-Y4 cells (generously donated by Lynda Bonewald) were grown in $\alpha$-MEM with $2.5 \%$ fetal calf serum (FCS) and $2.5 \%$ FBS in collagen-coated surface (collagen solution from calf skin (Sigma-Aldrich)), respectively as previously described (Ardura et al. 2018). All cells were cultured with penicillin (100 units/mL) and streptomycin $(100 \mu \mathrm{g} / \mathrm{mL})$ in a $5 \% \mathrm{CO}_{2}$ humidified incubator at $37^{\circ} \mathrm{C}$. TRAMP-C1, MC3T3-E1, MLO-Y4 and RAW 264.7 cells were incubated with $5 \mathrm{ng} / \mathrm{mL}$ MINDIN (R\&D Systems) for $6 \mathrm{~h}, 24 \mathrm{~h}$ or 15 days, when appropriate. To avoid effects of degradation during long exposures of the peptide we changed the cell culture medium every $48 \mathrm{~h}$ and included a fresh MINDIN dose every 2 days over the 15-day treatment. We confirm the suitability of these cells and markers to be used in the TRAMP-C1 mouse model. In this regard, MINDIN and the prostate-specific marker prostate stem cell antigen (PSCA) were specifically expressed in TRAMP-C1 cells but not in osteoblastic MC3T3-E1 or osteocytic MLO-Y4 cells (Supplementary Fig. 1A and B, see section on supplementary materials given at the end of this article). Similarly, MINDIN secretion has been described in TRAMP-C1 (Ardura et al. 2019) cells but not in MC3T3-E1 or MLO-Y4 cells (Supplementary Table 1).

Conditioned medium of TRAMP-C1 cells was obtained as follows: TRAMP-C1 cells were transfected with scrambled or MINDIN siRNAs for $24 \mathrm{~h}$. Then, cells were washed with PBS and incubated with FBS-depleted DMEM for $24 \mathrm{~h}$. Each conditioned medium was collected and added to bone cells at a 1/4 dilution in MC3T3-1 or MLO-Y4 corresponding culture medium.

\section{Secretome mass spectrometry analysis}

Initially, protein extracts $(50 \mu g)$ from TRAMP-C1, MC3T3-E1 and MLO-Y4 cells conditioned mediums were separated by PAGE under reducing conditions according to Laemmli, with a $12.5 \%$ separating gel and a $5 \%$ stacking gel. Protein staining was carried out with GelCode Blue Stain Reagent (Thermo Scientific). Separation of proteins and gel excision were carried out essentially as previously described (Ardura et al. 2019). The peptide extracts were combined into three pools of discontinuous bands to reduce the analysis by liquid chromatography-mass spectrometry (LC-MS) to four runs per sample. Peptides were detected in survey scans from 400 to $1600 \mathrm{amu}$ ( 1 uscan), followed by 20 data-dependent MS/MS scans (Top 20), using an isolation width of $2 \mu$ (in mass-tocharge ratio units), normalized collision energy of $35 \%$, and dynamic exclusion applied during 30-s periods.
Processing of the MS data was carried out as previously described (Ardura et al. 2019). Peptide identification from raw data was carried out using the SEQUEST algorithm (Proteome Discoverer 1.3, Thermo Scientific).

\section{Cell silencing and inhibition}

TRAMP-C1 and MC3T3-E1 cellswere silenced with a mixture of three siRNA (each at $20 \mathrm{nM}$ ) against different coding sequences of mouse MINDIN (s97640; s97638; s87252; Life Technologies) or with two siRNAs against different coding sequences of mouse $\beta$-catenin (s63418; s63419; Life Technologies, each at $20 \mathrm{nM}$ ), respectively, using Lipofectamine RNAiMax (Life Technologies) overnight at $37^{\circ} \mathrm{C}$, following the manufacturer's instructions. A scrambled sequence (control siRNA-A; Santa Cruz Biotechnology) was used as a negative control for evaluating RNAi off-targeted effects, and in order to verify the accuracy of gene-specific siRNA-dependent changes in different parameters evaluated. Efficiency of MINDIN or $\beta$-catenin silencing, assessed by real-time PCR, represented $85 \% 48 \mathrm{~h}$ after transfection and $60 \%$ up to 15 days after transfection (data not shown).

To inhibit focal adhesion kinase (Fak) and Src kinase addition of $1 \mu \mathrm{M}$ Fak inhibitor 14 (Merck) and $1 \mu \mathrm{M}$ saracatinib (Santa Cruz) for $24 \mathrm{~h}$ was performed when appropriate, respectively.

\section{Animal model}

Three-month-old C57BL/6 male mice (Charles River) were placed in cages under standard conditions (room temperature $20 \pm 0.5^{\circ} \mathrm{C}$, relative humidity $55 \pm 5 \%$ and illumination with a $12 \mathrm{~h} / 12 \mathrm{~h}$ light/dark photoperiod), without restriction of movement and were maintained on a standard pellet diet (Teklad Global 18\% Protein Rodent Diet, Envigo Madison, WI, USA) and tap water ad libitum. Surgical interventions were performed under aseptic conditions in anaesthetized mice by isoflurane inhalation/injection of xylazine $(10 \mathrm{mg} / \mathrm{kg})$ and ketamine $(25 \mathrm{mg} / \mathrm{kg})$. Briefly, mice were injected in the right posterior prostatic lobe through a midline lower abdominal incision with vehicle (phosphate buffer saline (PBS)) or $5 \times 10^{5}$ TRAMP-C1 cells $/ 50 \mu \mathrm{L}$, transfected with scrambled siRNAs or three MINDIN siRNAs (s97640; s97638; s87252) (Life Technologies), harvested after mild trypsinization and PBS washing, as previously described by our group (Ardura et al. 2019). A well-localized bleb within the injected prostatic lobe was considered a technically acceptable injection. The abdominal cavity, muscle and 
skin were closed with surgical staples. After 1 month, primary tumors were extracted and stored in TRIzol for real-time PCR analysis. We chose 1 month after orthotopic injection to ensure the presence of primary prostate tumors and avoid any early homing of TRAMP-C1 cells to the bone tissue. One month of tumor incubation is not sufficient to cause metastasis in the TRAMP-C1 model (a 18-30-week time period is required (Somers et al. 2003)). In this regard, no metastases were detected in any organ extracted. This model allows us to study the early effects of prostate tumors on bone tissue before cells metastasize. Next, we collected two different bones, namely femur and tibiae for bone histomorphometry and mRNA evaluation, respectively. Experimental protocols were approved by the Institutional Animal Care and Use Committee of San Pablo CEU University.

\section{Bone histomorphometry}

Bone histomorphometry was performed as previously described (Nuche-Berenguer et al. 2011). The femora specimens were dehydrated in graded ethanol and embedded in methylmethacrylate. Seven micron-thick sagittal longitudinal sections of the femora obtained with a rotation microtome for hard materials (Leica RM2255, Leica Microsystems) were stained with Goldner's trichrome. Histomorphometric measurements were performed using a light microscope with a reticulemounted eyepiece grid, and the following parameters were calculated according to the American Society for Bone and Mineral Research recommendations. We used the standardized nomenclature, symbols, and units of the ASBMR Histomorphometry Nomenclature Committee for bone histomorphometry (Dempster et al. 2013): bone volume per total tissue volume ratio (BV/TV), trabecular thickness (Tb.Th), trabecular separation (Tb.Sp), trabecular number (Tb.N), osteoblast number/bone perimeter $(\mathrm{N} . \mathrm{Ob} / \mathrm{Pm})$ and osteoclast number/bone perimeter (N.Oc/Pm).

\section{Real-time PCR}

Total RNA was isolated from mouse tibiae samples stored in RNAlater or from bone cells by a standard procedure (TRIzol, Life Technologies), and $2 \mu \mathrm{g}$ of this RNA was retrotranscripted with cDNA high-capacity retrotranscription kit (Applied Biosystems) following manufacturer's instructions. Gene expression was analyzed by real-time PCR using an ABI PRISM 7500 system (Applied Biosystems). Real-time PCR was done using Sybr premix ex Taq (Takara) with the following mouse-specific primers for prostate stem cell antigen (PSCA): 5'-TTCTCCTGCTGGCCACCTAC-3' (sense) and 5'-GCAGCTCATCCCTTCACAAT-3' (antisense) (Ardura et al. 2019); RANK-L: 5'-TGTACTTTCGAGCGCAGATG-3' (sense) and 5'-AGGCTTGTTTCATCCTCCTG-3' (antisense) (Arduraetal.2019);OPG:5'-CAGAGCGAAACACAGTTTG-3' (sense) and 5'-CACACAGGGTGACATCTATTC-3' (antisense) (Ardura et al. 2019); osteocalcin: 5'-GCAATAAGGTAGTGAACAGACTCC-3' (sense) and 5'-CCATAGATGCGTTTGTAGGCGG-3' (antisense) (Ardura et al. 2019); bone alkaline phosphatase: 5'-CCAGAAAGACACCTTGACTGTGG-3' (sense) and 5'-TCTTGTCCGTGTCGCTCACCAT-3' (antisense) (Ardura et al. 2019); Runx2: 5'-CCTGAACTCTGCACCAAGTCCT-3' (sense) and 5'-TCATCTGGCTCAGATAGGAGGG-3' (antisense) (Ardura et al. 2019); TRAP: 5'-CACGAGAGTCCTGCTTGTC-3' (sense) and 5'-AGTTGGTGTGGGCATACTTC-3' (antisense) (Ardura et al. 2019); Wnt11: 5'-GCTGGCACTGTCCAAGACTC-3' (sense) and 5'-CTCCCGTGTACCTCTCTCCA-3' (antisense) (Touma et al. 2017). Alternatively, real-time PCR was done using predeveloped fluorogenic mouse-specific TaqMan MGB probes for MINDIN (Mm00513596_m1) (Life Technologies). The mRNA copy numbers were calculated for each sample by using the cycle threshold $(\mathrm{Ct})$ value. $18 \mathrm{~S}$ or actin rRNA (housekeeping genes) were amplified in parallel with tested genes. The number of amplification steps required to reach an arbitrary intensity Ct was computed. The relative gene expression in cell assays was defined as the relative expression, compared with control,

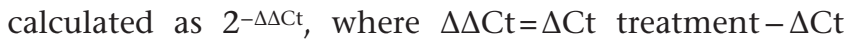
control and $\Delta \mathrm{Ct}=\mathrm{Ct}$ target gene $-\mathrm{Ct} 18 \mathrm{~S}$. Gene expression of animal samples was represented as individual data points by calculating the $2-\Delta \mathrm{Ct}$, as previously described (Schmittgen \& Livak 2008). Amplicon specificity was confirmed as the presence of a single peak in the melting curve for each qPCR reaction.

\section{Western blot analysis}

Total cell protein extracts were obtained with $50 \mathrm{mM}$ Tris$\mathrm{HCl}, \mathrm{pH} 7.4,150 \mathrm{mM} \mathrm{NaCl}, 1 \mathrm{mM}$ EDTA, 1\% Triton X-100, $1 \%$ sodium deoxycholate, and $0.1 \%$ SDS, supplemented with protease inhibitor cocktail (Sigma-Aldrich), and phosphatase inhibitor cocktail Set II (Calbiochem). To isolate nuclear fractions a standardized nuclear fractioning protocol was followed (Abcam). Protein content in cell extracts was determined by the bicinchoninic acid (BCA) assay (Thermo Fisher Scientific), using BSA as standard. 
Cell proteins (30-60 $\mu \mathrm{g} / \mathrm{lane})$ were separated on $5-10 \%$ polyacrylamide-SDS gels under reducing conditions. After electrophoresis, samples were transferred onto nitrocellulose membranes (Bio-Rad), blocked with 5\% defatted milk in $50 \mathrm{mmol} / \mathrm{L}$ Tris- $\mathrm{HCl}, \mathrm{pH} 7.5$, and $150 \mathrm{mmol} / \mathrm{L} \mathrm{NaCl}$ with $0.05 \%$ Tween 20 , and incubated overnight at $4^{\circ} \mathrm{C}$ with the following rabbit polyclonal antibodies (dilution): phosphorylated (p)- $\beta$-catenin (1:1000) and total $\beta$-catenin (1:2000) (Cell Signaling Technology). $\alpha$-Tubulin (Sigma-Aldrich) was used as a loading control. After extensive washing, the membranes were incubated with peroxidase-conjugated goat antirabbit IgG and developed by ECL chemiluminiscence (GE Healthcare). Densitometric values of fluorogram bands were normalized to those of the corresponding $\alpha$-tubulin band.

\section{Immunofluorescence and immunohistochemistry}

Cells grown on coverslips were stimulated with MINDIN, fixed in $4 \%$ paraformaldehyde and permeabilized with $0.1 \%$ Triton-X100 for 5 min. After blocking with 10\% BSA for $1 \mathrm{~h}$, they were incubated with a total $\beta$-catenin antibody (1:500) (Cell Signaling Technology) overnight at $4^{\circ} \mathrm{C}$, followed by an Alexa 543 secondary antibody (1:500) for $1 \mathrm{~h}$ at room temperature. Absence of primary antibody was used as negative control. Samples were mounted in Fluorsave (Merck) and examined using a Leica DM-IRB epifluorescence microscope.

Deparaffinized and rehydrated tissue sections were treated for 30 min with hydrogen peroxide $0.3 \%$ in PBS to block endogenous peroxidase. Pretreatment of sections by heat (using microwave for two consecutive times of 10 min each at maximum and average power respectively) in citrate buffer, $\mathrm{pH}$ 6.0, was performed to enhance immunostaining. To detect cytokeratins, the samples were incubated overnight at $4{ }^{\circ} \mathrm{C}$ with the anti-cytokeratin pan (Invitrogen) at 1:100 in PBS containing 2\% donkey serum. Sections were first incubated for $10 \mathrm{~min}$ at room temperature with biotinylated anti-mouse IgG secondary antibody (IHC Kit ref. 95-9943B, Life Technologies) and then with streptavidin peroxidase (Histostatin-SP IHC Kit ref. 95-9943B, Life Technologies). Finally, immunostaining was visualized using diaminobenzidine (Liquid DAB Substrate Kit ref. 002014, Invitrogen). Nuclear contrast was obtained with Harris hematoxylin. Finally, sections were dehydrated in ethanol and mounted into a synthetic resin (Depex, Serva, Heidelberg, Germany). Pictures were obtained using a Leica DFC 425 camera connected to Leica 5500B microscope.

\section{Adhesion assay}

The adhesion of TRAMP-C1 adenocarcinoma cells to bone surfaces, MLO-Y4 osteocytes or MC3T3 pre-osteoblasts in vitro, was assessed by seeding calcein-AM-labeled TRAMP-C1 cells in deparaffined bone sections of control, scrambled siRNA tumor or MINDIN siRNA tumor groups or a 24-well plate pre-inoculated with collagen, MLO-Y4 or MC3T3-E1 cells at confluence tretated or not with MINDIN for $24 \mathrm{~h}$. TRAMP-C1 cells were pre-incubated with $2 \mu \mathrm{M}$ calcein-AM (Thermo Scientific) for $30 \mathrm{~min}$, subsequently washed with PBS and seeded onto MLO-Y4 or MC3T3-E1 covered well surfaces. Non-adherent cells were removed after $30 \mathrm{~min}$ of incubation with complete medium followed by plate washing with PBS. Next, adherent cells were fixed with $4 \%$ paraformaldehyde and images were obtained with a fluorescence microscope (Leica DM5500B). The number of fluorescence-labeled cells was counted in ten different fields per condition.

\section{Statistical analysis}

All results are expressed as means \pm s.E. Differences among conditions were evaluated by nonparametric variance analysis (Kruskal-Wallis) followed by Dunn's test. A Mann-Whitney test was performed to analyze the differences between vehicle control or scrambled siRNA samples and MINDIN-stimulated or MINDIN siRNA transfected samples in vitro.

\section{Results}

\section{MINDIN expression by primary prostate tumors induces pre-metastatic modifications of bone microarchitecture and gene expression}

Herein, we characterize for the first time, structural and gene expression patterns that could favor metastasis of prostate tumor cells in the bone microenvironment before the settlement and propagation of metastasis. We use a TRAMP-C1 mouse model that recapitulates progression of prostate cancer, from hyperplasia to prostatic intraepithelial neoplasia to potentially metastasize to lymphatic nodes, lungs and bone, as well as contains an intact immune system in which the initial phases of tumor progression and communication with bone are not compromised (Gingrich et al. 1996, Ardura et al. 2019).

The histomorphometric assessment of bone microarchitecture in this TRAMP-C1 mouse model showed decreased bone volume/total volume, 
A

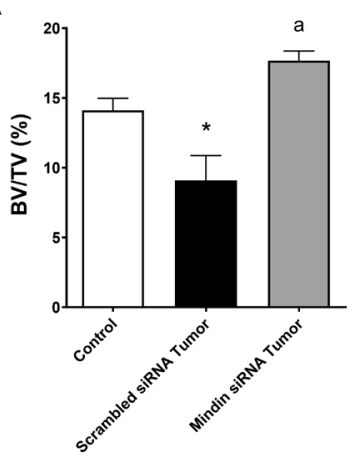

C

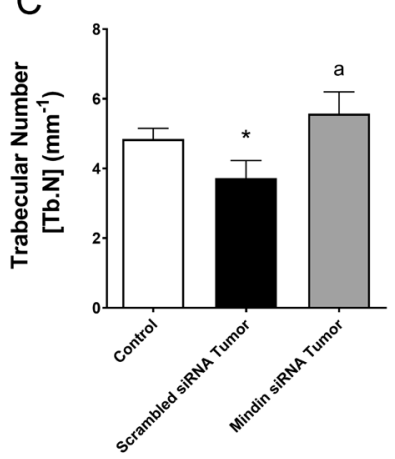

E

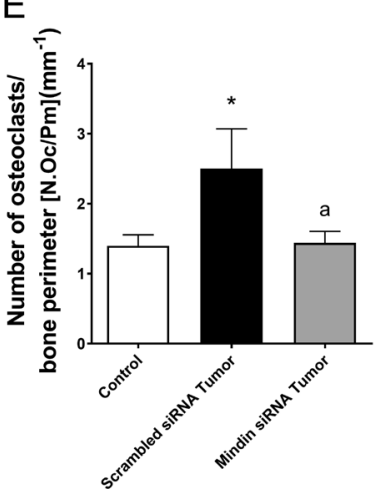

B

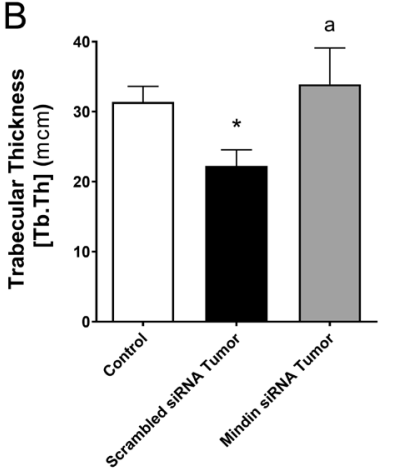

D

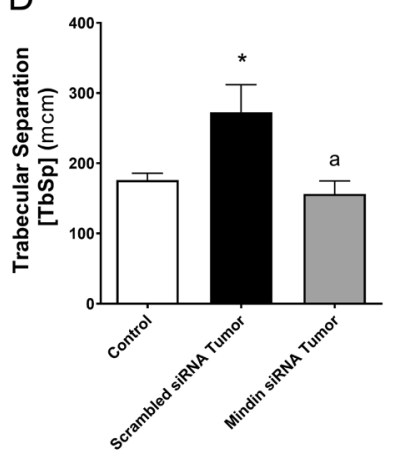

$\mathrm{F}$

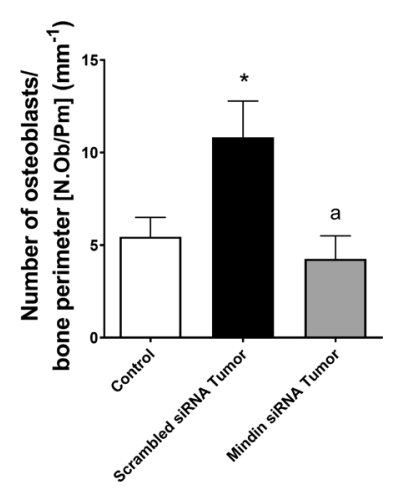

Figure 1

MINDIN induces microstructural changes in femora of mice with TRAMP-C1-generated prostate tumors. Bone histomorphometric parameters were evaluated in femora of control (PBS injection in the prostate gland, without tumor), scrambled siRNA tumor (presence of tumor caused by injection of TRAMP-C1 cells transfected with scrambled siRNA in the prostate gland) and MINDIN siRNA tumor (presence of tumor caused by injection of TRAMP-C1 cells transfected with MINDIN siRNA in the prostate gland) mice as described in materials and methods. BV/TV: Bone volume/total volume; Tb.Th: Trabecular thickness; Tb.N: trabecular number; Tb.Sp: Trabecular separation; N.Oc/Pm: Osteoclast number/ bone perimeter; N.Ob/Pm: Osteoblast number/bone perimeter. The data are represented as the mean \pm S.E.M. ( $n=7-10$ per group). $* P<0.05$ vs control; a $P<0.05$ vs scrambled siRNA tumor.

trabecular thickness and trabecular number (Fig. 1A, B and $C$ ) and increased trabecular separation and number of osteoclasts and osteoblasts (Fig. 1D, E and F) in femora of mice with prostate tumors compared to control mice (without prostate tumors). Increased number of osteoclasts and osteoblasts in animals that harbor primary prostate tumors suggest altered skeletal remodeling processes that could lead to increased bone resorption. Altered bone remodeling could in turn be responsible for the aforementioned decreased levels of bone structure parameters as it has been previously described in other prostate animal models (Logothetis et al. 2018). Analysis of bone remodeling genes revealed increased expression and enzymatic activity of the osteoclast resorption marker TRAP in tibiae of the tumor group compared to control mice (Fig. 2A and I). Other genes involved in bone formation (Runx2, osterix, osteocalcin), resorption (RANK-L and RANK) or OPG, a decoy receptor for the RANKL-RANK interaction, showed no significant upregulation (Fig. 2C, D, E, F, G and H).

We hypothesized that factors secreted by prostate tumors induce the aforementioned microstructural and gene expression changes in bone before settlement of tumor cells in bone. We recently described overexpression of MINDIN, a member of the spondin family of bone regulatory proteins, in the secretome of prostate tumor TRAMP-C1 and LNCaP cells by proteomic analysis and in primary tumors of the TRAMP-C1-induced prostate cancer model (Ardura et al. 2019). Our observations revealed that this protein mediated some bone-tumor crosstalk actions (Ardura et al. 2019) and suggested the possible role of MINDIN as an inductor of pre-metastatic changes in bone. In this regard, MINDIN silencing of TRAMP-C1 cells injected in the prostate reversed the histomorphometric and gene expression changes observed in femora and tibiae of our mouse model (Figs 1A, B, C, D, E, F and 2A, B, C, D, E, F, G, H, I). We have confirmed in the TRAMP-C1-induced prostate cancer model that primary tumors overexpress MINDIN, RANK-L and the prostate tumor marker PSCA, whereas MINDIN-silenced tumors presented low levels of MINDIN and RANK-L expression but maintained high levels of PSCA (Ardura et al. 2019). MINDIN expression in prostate tumors was 35-fold higher compared to controls. In MINDIN-silenced tumors, expression of MINDIN was reduced to 1.4-fold compared to controls. MINDIN expression in primary prostate (c) 2020 Society for Endocrinology Published by Bioscientifica Ltd. Printed in Great Britain 
A
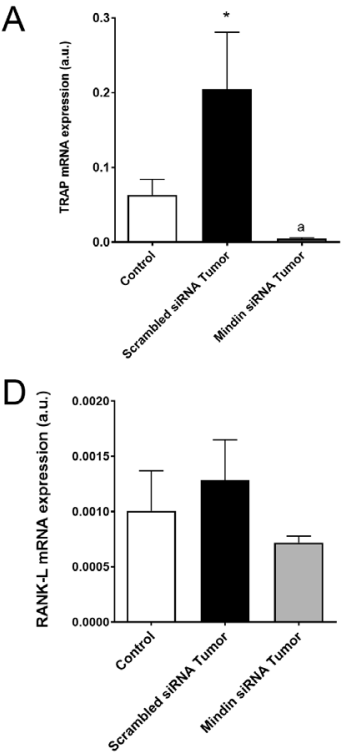

B

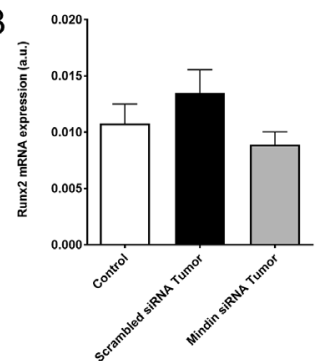

E

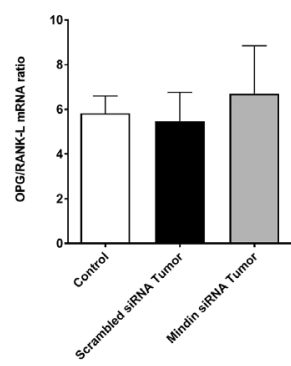

C

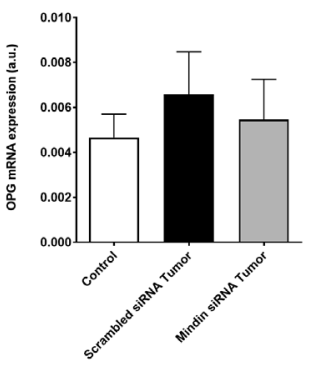

$\mathrm{F}$

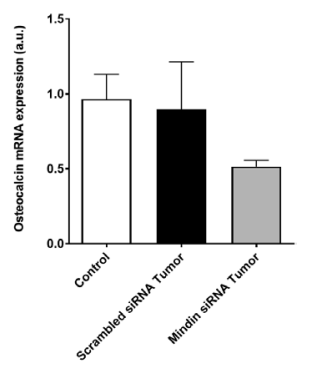

G
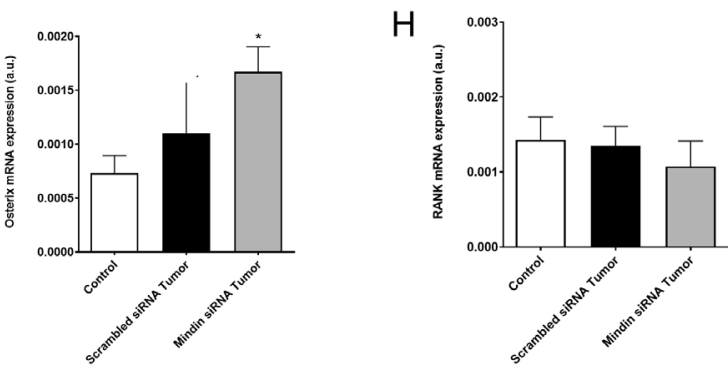

I

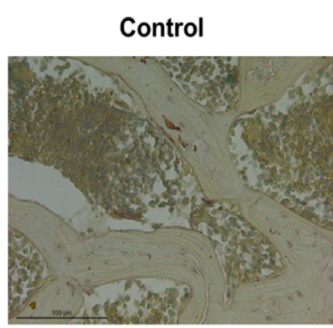

Scrambled siRNA Tumor

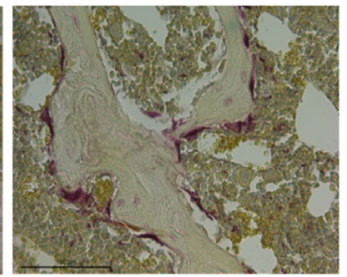

Mindin siRNA Tumor

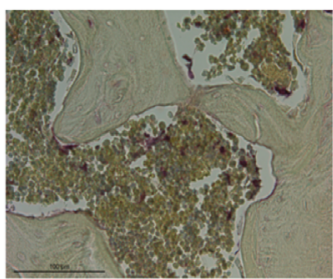

\section{Figure 2}

TRAP is overexpressed in tibiae of mice that harbor TRAMP-C1-induced prostate tumors via MINDIN. (A) Tartrate-resistant acid phosphatase (TRAP), (B) Runx2, (C) OPG, (D) RANK-L, (E) OPG/ RANK-L, (F) Osteocalcin, (G) Osterix and (H) RANK mRNA expression was assessed by real-time PCR. mRNA expression was assessed in tibiae of the following conditions: control (PBS injection in the prostate gland, without primary tumor), scrambled siRNA tumor (presence of primary tumor caused by injection of TRAMP-C1 cells transfected with scrambled siRNA in the prostate gland) and MINDIN siRNA tumor (presence of tumor caused by injection of TRAMP-C1 cells transfected with MINDIN siRNA in the prostate gland). (I) Representative images of TRAP staining analyzed in femora bone sections of the different groups are shown. Scale bar denotes $100 \mu \mathrm{m}$. The data are represented as the mean \pm S.E.M. $(n=7-10$ per group). ${ }^{*} P<0.05$ vs control; a $P<0.05$ vs scrambled siRNA tumor. A full colour version of this figure is available at https://doi.org/10.1530/ ERC-20-0116. tumors in the different experimental conditions used was the following (mean \pm s.E.M.); control: $0.00014 \pm 0.00005$, scrambled siRNA-tumor: 0:005 \pm 0.002 and MINDIN siRNA-transfected tumors: $0.0002 \pm 0.00005$.

Even though the TRAMP model can potentially develop bone metastases after several weeks (Gingrich et al. 1996), analysis of the expression of prostate tumor cell markers in entire femora and tibiae of mice corresponding to our groups of study showed negligible levels of PSCA and MINDIN gene expression levels - similar to those observed in the non-tumoral group - (Fig. 3). In addition, there was no cytokeratin labeling in bones of the studied groups (data not shown) confirming the absence of bone metastases after 1 month of TRAMP-C1 orthotopic injection.
These results suggest that MINDIN-expressing prostate tumors induce alterations in the bone microenviroment in the absence of prostate cancer metastases.

\section{MINDIN increases prostate adenocarcinoma cell adhesion to bone and Wnt11 expression}

MINDIN has been reported to increase adhesion of different types of cells to the extracellular matrix, including neutrophils, macrophages or lymphocytes (Jia et al. 2005, Li et al. 2006). Thus, we wondered whether secretion of MINDIN by prostate tumors could increase adenocarcinoma cell adhesion to bone surfaces. TRAMP-C1 cells showed increased adhesion to trabecular 

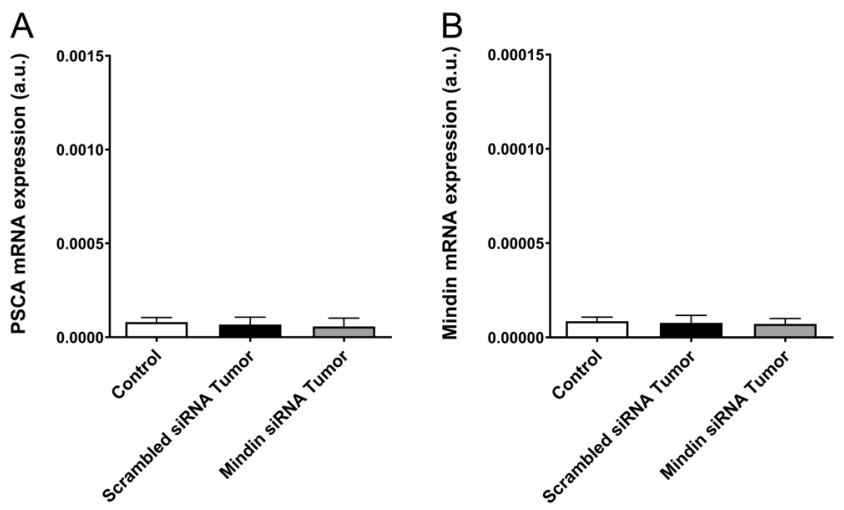

Figure 3

Absence of bone metastases in the experimental mouse model of prostatic tumor induced by TRAMPC-1. (A) Prostate stem cell antigen (PSCA) and (B) MINDIN mRNA expression in control (PBS injection in the prostate gland, without tumor), scrambled siRNA tumor (presence of tumor caused by injection of TRAMP-C1 cells transfected with scrambled SiRNA in the prostate gland) and MINDIN siRNA tumor (presence of tumor caused by injection of TRAMP-C1 cells transfected with MINDIN SiRNA in the prostate gland) entire tibiae from mice assessed by real-time PCR. The data are represented as the mean \pm S.E.M. ( $n=7-10$ per group). $* P<0.05$ vs control; a $P<0.05$ vs scrambled siRNA tumor.

bone ex vivo in the prostate tumor group compared to the control group (Fig. 4A). Nonetheless, MINDIN silencing in the primary tumor inhibited TRAMP-C1 adhesion to trabecular bone (Fig. 4A). Even though Fig. 3 shows no TRAMP-C1 metastasis to the bone in vivo in our model, our ex vivo results suggest that MINDIN can potentially promote prostate cancer cell adhesion to pre-metastatic niches of the bone microenvironment. To elucidate whether extracellular matrix or bone cell surfaces were necessary for MINDIN-dependent adenocarcinoma cell adhesion to bone, we incubated MC3T3 osteoblast-like cells, osteocyte-like MLO-Y4 cells, and collagen I-coated surfaces with MINDIN. Incubation of collagen-coated surfaces with MINDIN slightly increased the number of TRAMP-C1 cells attached to the plate surface compared to uncoated or collagen-coated surfaces without peptide incubation (Fig. 4B). Moreover, the number of TRAMP-C1 cells attached to MINDIN-stimulated MC3T3 or MLO-Y4 cells was significantly higher compared to collagen-coated surfaces incubated with MINDIN or with non-stimulated cells (Fig. 4B). Furthermore, TRAMP-C1 adhesion to MC3T3 osteoblastic cells was higher than to osteocyte MLO-Y4 cells (Fig. 4B). These data could point out to a role of MINDIN on tumor cell-bone cell adhesion.

Given that osteogenic actions associated with Wnt11 and R-spondin 2 upregulation have been previously reported in osteoblasts (Friedman et al. 2009), we tested whether Wnt11 could be a mediator of MINDIN in prostate cancer cells. In this regard, we observed that MINDIN-silenced TRAMP-C1 cells expressed lower mRNA levels of Wnt11 compared to scrambled-silenced controls (Fig. 4C).

\section{MINDIN increases the expression of bone formation genes and mineralization of osteoblasts and osteoclastic differentiation}

We next tested the effects of MINDIN on different bone cells, namely osteoblastic MC3T3-E1, osteocyte-like MLO-Y4, and pre-osteoclast RAW 264.7 cells. Increased gene expression of the bone remodeling inhibitor osteoprotegerin (OPG) and osteoblastic differentiation markers including Runx2, osteocalcin, and osterix, and decreased RANK-L expression was observed in MC3T3 cells after MINDIN stimulation for $6 \mathrm{~h}$ and $24 \mathrm{~h}$ (Fig. 5A, B, C, D, E and F). Similar effects were observed in MC3T3-E1 cells treated with conditioned medium of scrambled siRNA-transfected TRAMP-C1 cells (Fig. $5 \mathrm{G}, \mathrm{H}, \mathrm{I}, \mathrm{J}, \mathrm{K}$ and $\mathrm{L}$ ) and in MLO-Y4 cells stimulated with MINDIN (Fig. 6) or with conditioned medium of scrambled siRNA-transfected TRAMP-C1 cells (Fig. 6G, H, $\mathrm{I}$ and J). Interestingly, changes in bone markers induced by TRAMP-C1 conditioned medium in MC3T3-E1 (Fig. 5G, H, I, J, K and L) and MLO-Y4 (Fig. 6G, H, I and J) cells were inhibited when stimulating with conditioned medium of MINDIN-silenced TRAMP-C1 cells instead.

Prolonged exposure of MC3T3-E1 cells for 15 days to MINDIN sustained Runx-2 and osteocalcin overexpression but did not affect osterix, OPG, or RANK-L levels (Supplementary Fig. 1C, D, E, F and G). In contrast, prolonged exposure of MLO-Y4 cells for 15 days to MINDIN did not sustain overexpression of any bone marker (Supplementary Fig. 1H, I, J and K).

In addition, incubation with MINDIN for $72 \mathrm{~h}$ or 21 days induced an increase in MC3T3 cell proliferation and MC3T3-E1-dependent deposition of bone mineral (calcium phosphate), respectively (Fig. 7).

On the other hand, RAW 264.7 monocytes stimulated with MINDIN showed increased levels of the receptor for RANK-L, RANK (Fig. 7C). Differentiation of RAW 264.7 monocytes to osteoclasts by incubation of these cells with RANK-L for 6 days and subsequent stimulation with MINDIN further increased the expression of TRAP, a marker of osteoclasts, in RAW 264.7 cells compared to incubation with RANK-L alone (Fig. 7D). (c) 2020 Society for Endocrinology Published by Bioscientifica Ltd. Printed in Great Britain 
A

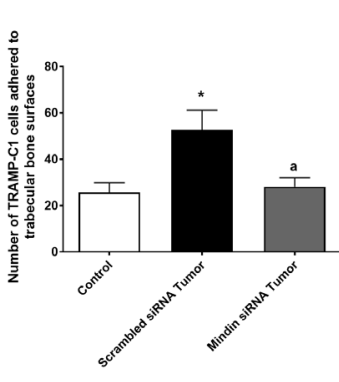

B

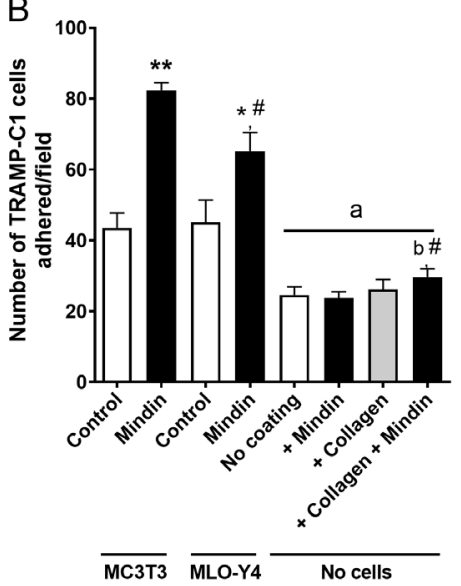

C

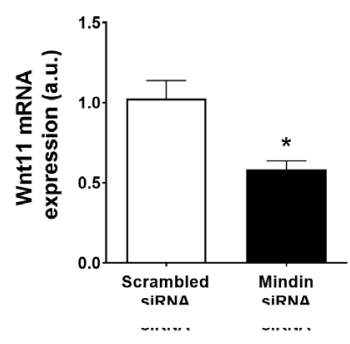

Bright field

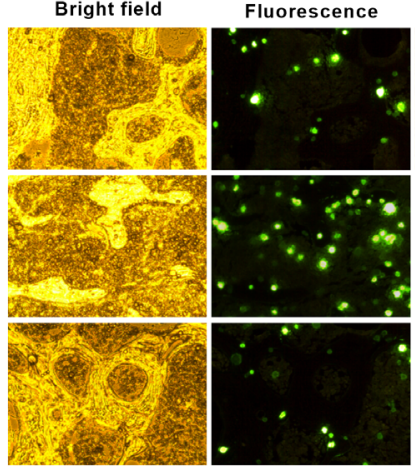

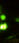
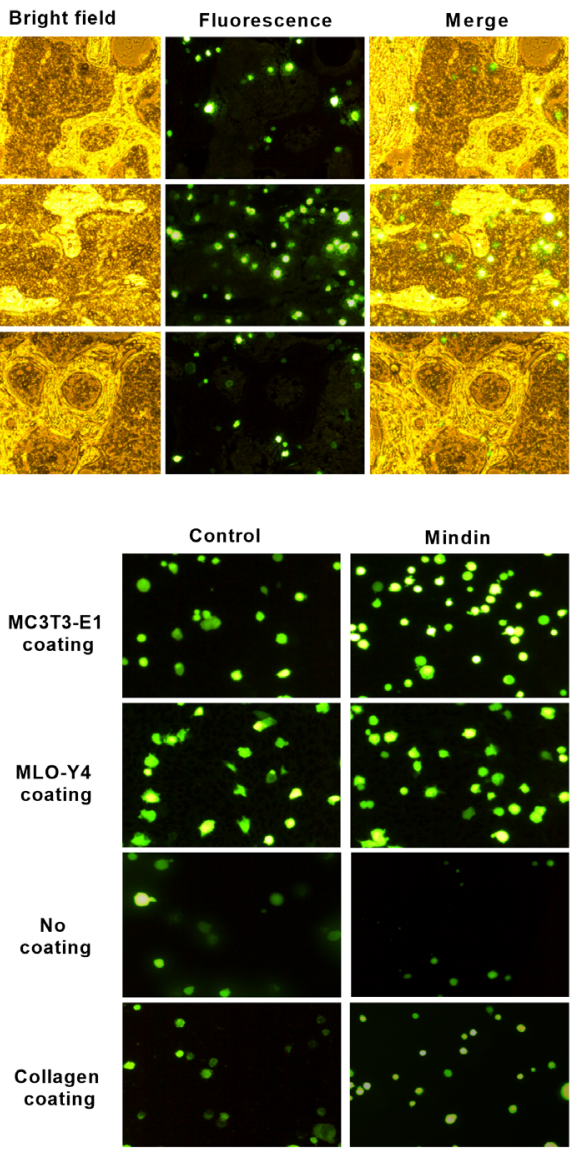

Figure 4

MINDIN increases adenocarcinoma TRAMP-C1 cell adhesion to osteoblastic-covered surfaces and Wnt11 expression. Number of TRAMP-C1 cells labeled with calcein-AM and adhered to bone surfaces in control (PBS injection in the prostate gland, without tumor), scrambled siRNA tumor (presence of tumor caused by injection of TRAMP-C1 cells transfected with scrambled siRNA in the prostate gland) and MINDIN siRNA tumor (presence of tumor caused by injection of TRAMP-C1 cells transfected with MINDIN siRNA in the prostate gland) mice (A), to confluent MC3T3-E1- or MLO-Y4-covered surfaces stimulated or not with MINDIN peptide $(5 \mathrm{ng} / \mathrm{mL})$ during $24 \mathrm{~h}$ or collagen-coated and non-coated plates is shown (B). Representing images from three experiments in triplicate are shown. (C) Wnt11 mRNA expression was assessed by real-time PCR in TRAMP-C1 cells after $24 \mathrm{~h}$ of scrambled or MINDIN siRNA transfection. The data are shown as the mean \pm S.E.M. of three experiments in triplicate. $* P<0.05$ vs corresponding control or scrambled siRNA transfection, $* \star P<0.01$ vs corresponding control, $\# P<0.05$ vs MC3T3 MINDIN-treated condition, a $P<0.05$ vs scrambled siRNA tumor or cell-coated conditions, ${ }^{b} \mathrm{p}<0.05$ vs corresponding condition without MINDIN treatment. A full colour version of this figure is available at https://doi. org/10.1530/ERC-20-0116.

\section{MINDIN stimulates $\beta$-catenin signaling pathway in osteoblast-like cells}

Other members of the TSR-1 superfamily that share some structural domains with MINDIN, namely R-spondins (de Lau et al. 2012), trigger changes in bone by regulating the $\beta$-catenin signaling pathway (Zhu et al. 2016). Given that $\beta$-catenin signaling has a key role in bone regulation (Baron \& Rawadi 2007), we wondered whether MINDIN effects on bone in our model could be caused by activation of the $\beta$-catenin signaling pathway. Stimulation of MC3T3 pre-osteoblastic cells with MINDIN induced $\beta$-catenin translocation to the nucleus (Fig. 8A), increased nuclear $\beta$-catenin levels (Fig. 8B), decreased $\beta$-catenin phosphorylation and increased total protein levels of $\beta$-catenin (Fig. 8C). Interestingly, $\beta$-catenin silencing inhibited MINDIN-dependent downregulation of RANK-L levels and upregulation of the OPG/RANK-L ratio in osteoblasts (Fig. 8D, E, F and G). However, $\beta$-catenin silencing did not inhibit MINDIN-dependent increase of osteoblast-adenocarcinoma cell adhesion (Fig. 9A) or MINDIN-induced expression of RANK and TRAP markers in non-differentiated or differentiated RAW 264.7, respectively (Fig. 9B and C). Another member of the spondin family of proteins, spondin 1 , has been associated with promotion of osteosarcoma cell migration and invasion through a focal adhesion kinase (Fak) and Src kinase-dependent pathway (Chang et al. 2015). Therefore, we tested the role of Fak and Src on MINDINinduced increase of osteoblast-adenocarcinoma cell 
A
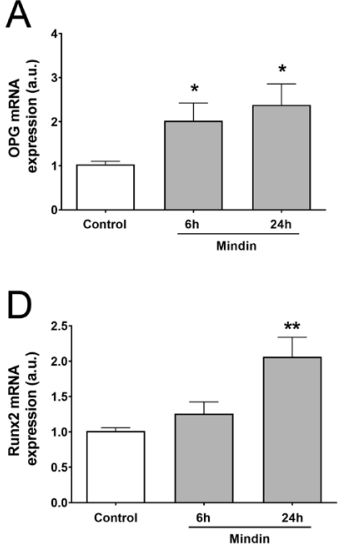

G
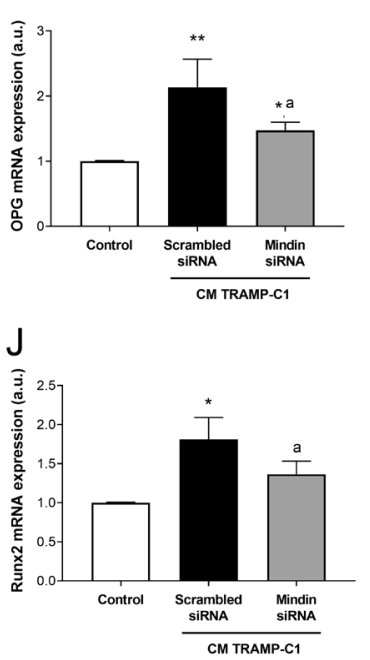

B

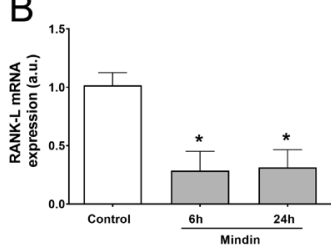

E

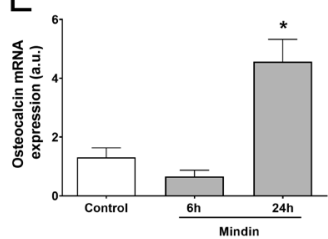

$\mathrm{H}$

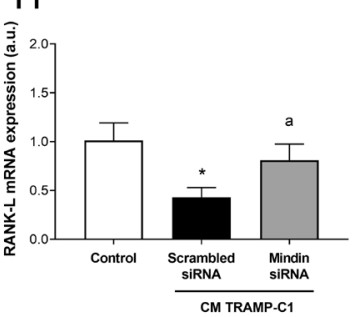

$\mathrm{K}$

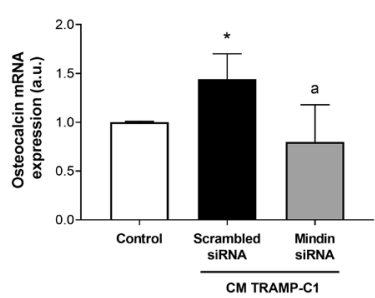

C

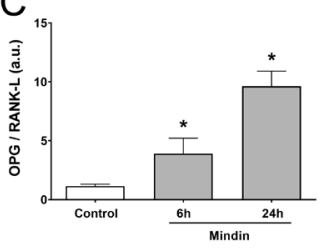

$\mathrm{F}$
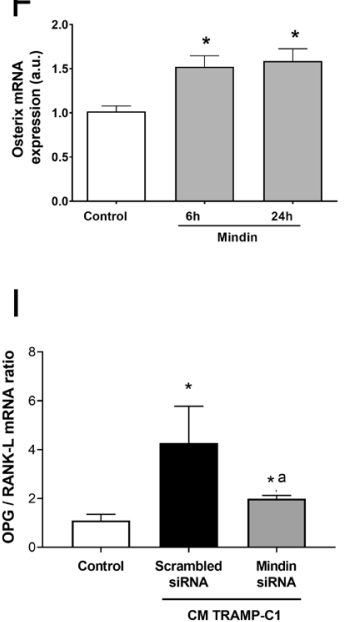

L

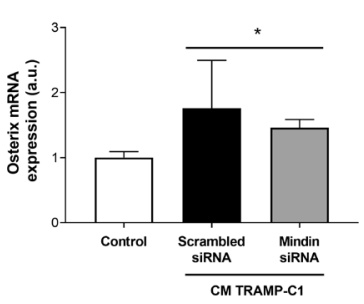

Figure 5

MINDIN and conditioned medium of TRAMP-C1 cells induce changes in bone remodeling markers in osteoblastic MC3T3-E1. MC3T3-E1 cells were stimulated with MINDIN $(5 \mathrm{ng} / \mathrm{mL})$ for 6 and $24 \mathrm{~h}$ (A, B, C, D, E and F) or with TRAMP-C1 conditioned medium (CM) for $24 \mathrm{~h}(\mathrm{G}, \mathrm{H}, \mathrm{I}, \mathrm{J}, \mathrm{K}$ and $\mathrm{L})$. Total cell RNA was isolated to assess mRNA levels of OPG (A and $\mathrm{G}$ ), RANK-L (B and H), OPG/RANK-L ratio (C and I), Runx-2 (D and J), osteocalcin (E and $K$ ) osterix ( $\mathrm{F}$ and $\mathrm{L}$ ) after 6-24 $\mathrm{h}$ stimulation with MINDIN or with conditioned medium (CM) of scrambled siRNA- or MINDIN siRNA-transfected TRAMPC-1 cells. Evaluations were performed by real-time PCR. Experimental values are mean \pm S.E.M. from three independent experiments. $* P<0.05$ vs control; $* * P<0.01$ vs control; a $P<0.05$ vs CM of scrambled siRNAtransfected TRAMP-C1 cells. adhesion. We observed that treatment of MC3T3-E1 and MLO-Y4 cells with Fak inhibitor 14 and Saracatinib (Src kinase inhibitor) prior to MINDIN stimulation decreased adhesion of TRAMP-C1 cells to both bone cells (Fig. 9D and data not shown). These results suggest that Fak and Src kinase play an important role in prostate cancer cell adhesion to areas rich in bone cells.

\section{Discussion}

Primary tumors create favorable pre-metastatic niches in secondary organs for subsequent metastases (Liu \& Cao 2016). In the initial phase of pre-metastatic niche formation, primary tumor cells produce various soluble factors to trigger the formation of an immature premetastatic niche (Liu \& Cao 2016). The discovery of specific factors involved in the formation of the premetastatic niche would help the development of future therapeutic strategies. In this regard, formation of a bone pre-metastatic niche by soluble factors is poorly defined in prostate cancer. Herein, we show that expression of the extracellular matrix protein MINDIN by prostate cancer cells induce changes in the bone microenvironment that could promote prostate cancer cell metastases.

We observed that TRAMP-C1-induced tumors in mice cause skeletal microarchitecture and gene expression changes with no detectable presence of metastatic adenocarcinoma cells in bone. MINDIN-dependent changes in osseous microarchitecture revealed a bone resorption pattern, as shown by decreased BV/TV, trabecular number and thickness and increased trabecular separation. Although prostate cancer metastases have been classically defined as mainly osteoblastic and associated with bone formation, they require a resorption phase in their initial steps (Jin et al. 2011), while developing mixed osteoblastic and osteoclastic lesions in more advanced stages (Jin et al. 2011). In this regard, we observed a higher number of osteoclasts and increased TRAP expression and staining in bones of prostate tumor mice. 

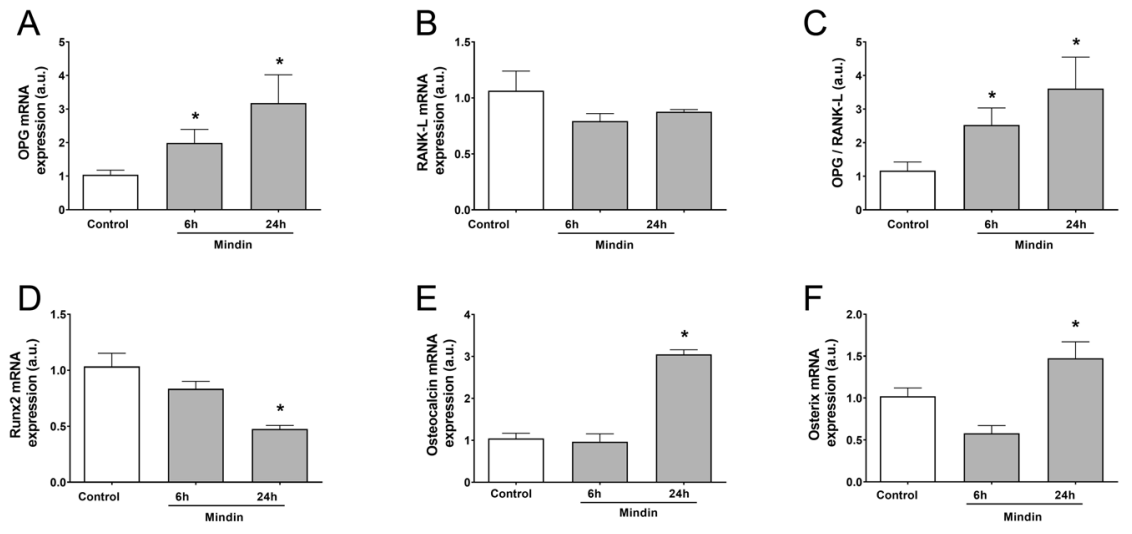
Figure 6
MINDIN and conditioned medium of TRAMP-C1 cells induce changes in bone remodeling markers in osteocytic MLO-Y4. MLO-Y4 cells were stimulated with MINDIN ( $5 \mathrm{ng} / \mathrm{mL})$ for 6 and $24 \mathrm{~h}$
( A, B, C, D, E and F) or with TRAMP-C1 conditioned medium (CM) for $24 \mathrm{~h}$ ( $\mathrm{G}, \mathrm{H}$, I and J). Total cell RNA was isolated to assess mRNA levels of OPG (A and G), RANK-L (B and H), OPG/RANK-L ratio ( $C$ and I), Runx-2 (D), osteocalcin (E and J) and osterix (F) after 6-24 h stimulation with MINDIN or with conditioned medium (CM) of scrambled siRNA- or MINDIN siRNA-transfected TRAMPC-1 cells. Evaluations were performed by real-time PCR. Experimental values are mean \pm S.E.M. from three independent experiments. ${ }^{*} P<0.05$ vs control; $* * P<0.01$ vs control; a $P<0.05$ vs CM of scrambled siRNA-transfected TRAMP-C1 cells.

c

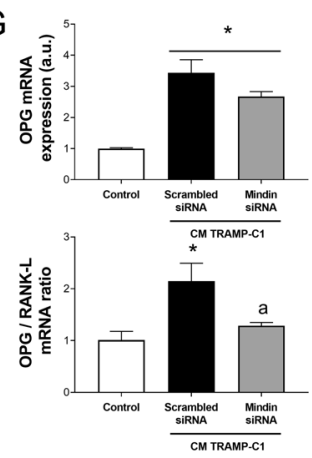

$\mathrm{H}$
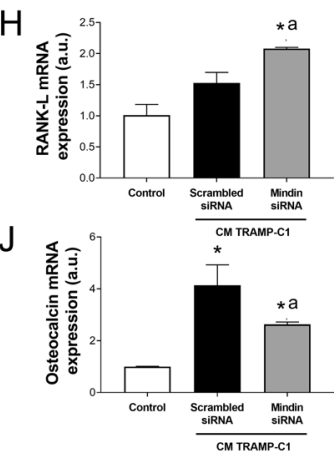

A

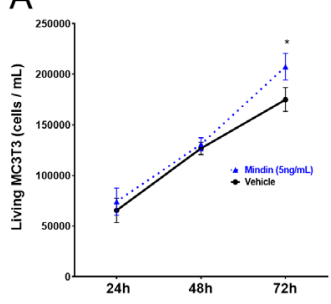

B

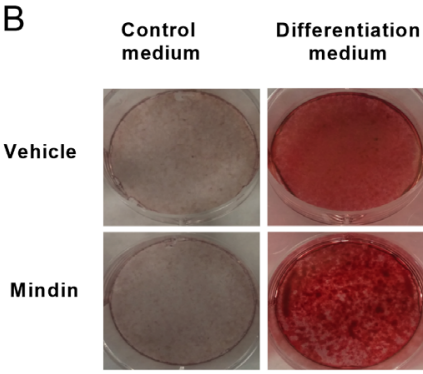

C

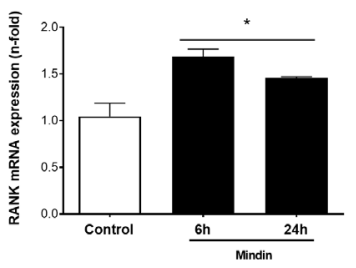

D

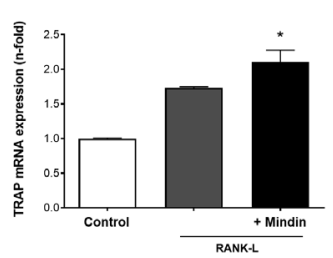

Figure 7

MINDIN induces cell mineralization and proliferation in osteoblastic MC3T3-E1 and triggers the expression of osteoclastic markers in RAW 264.7 macrophage-preosteoclastic cells. MC3T3-E1 cells were stimulated with MINDIN ( $5 \mathrm{ng} / \mathrm{mL}$ ) for 24,48 and $72 \mathrm{~h}$ (A) or 21 days (B). (A) Proliferation was assessed by trypan blue cell counting in a Neubauer chamber. (B) Deposition of bone mineral (calcium phosphate) by MC3T3-E1 osteoblastic cells was assessed using Alizarin red S to stain calcium deposits. Representative images of three independent experiments are shown. RAW 264.7 cells were stimulated with MINDIN (5 $\mathrm{ng} / \mathrm{mL}$ ) for 6 and $24 \mathrm{~h}$ (C) or 6 days (D). A full colour version of this figure is available at https://doi.org/10.1530/ERC-20-0116.

TRAP, a metalloenzyme that is characteristic for its expression in activated osteoclasts, also promotes metastasis-related cell properties in MDA-MB-231 breast cancer cells (Reithmeier et al. 2017) and has been described to be increased in bone metastases of advanced prostate cancer (Nordstrand et al. 2018).

On the other hand, increased osteoblast number in bones of prostate tumor-induced animals suggests that prostate tumors promote osteoblast differentiation and activation as evidenced here, even though osteoclastic activity and thus bone resorption is predominant in premetastatic bone. Although Runx 2 was not substantially increased in vivo, our in vitro results show that Runx2 levels are upregulated by MINDIN in osteoblasts. In this regard, an intra-tibial metastasis model of prostate cancer showed that high Runx2 levels were associated with development of large tumors, increased expression of metastasis-related genes (Matrix metalloproteinase 9 and 13, VEGF, Osteopontin), and secreted bone resorbing factors (PTHrP, IL-8) promoting osteolytic disease (Akech et al. 2010). These observations suggest that Runx2 could be a pivotal factor controlling both osteoblastic and osteoclastic metastatic processes in prostate cancer.

Our data reveal that MINDIN could be a key factor that promotes increased prostate adenocarcinoma cell adhesion to bone surfaces. In vitro data suggest that MINDIN preferentially increases adhesion of prostate cancer cells to 
A

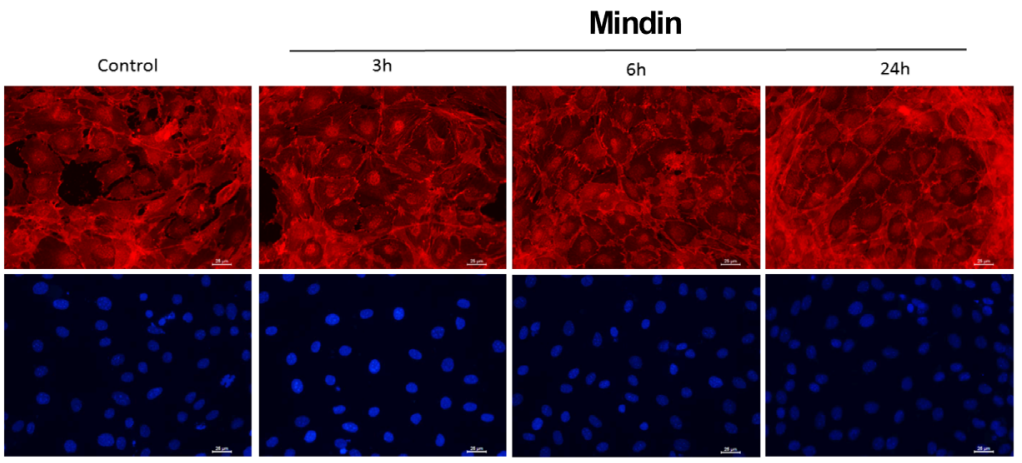

B

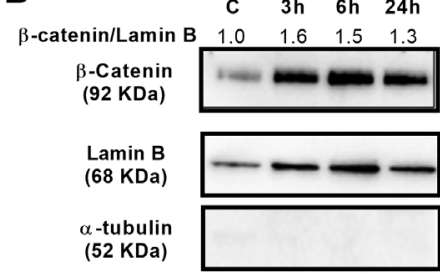

D

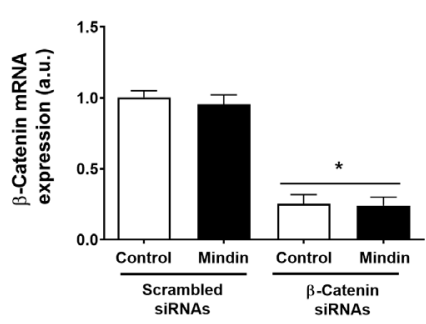

F

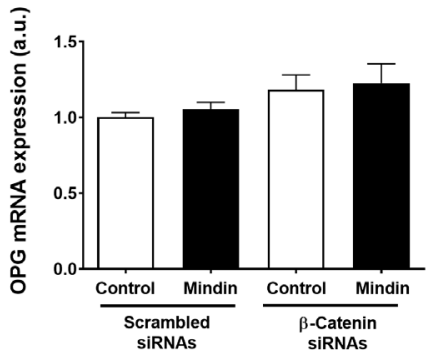

C

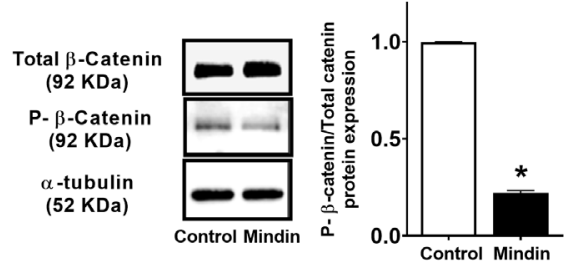

$E$

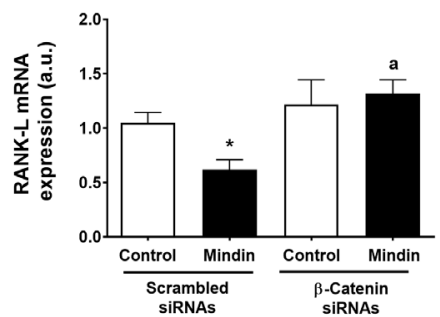

G

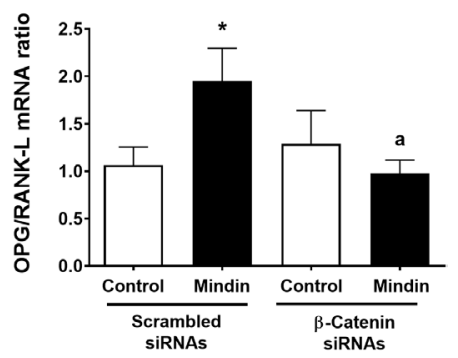

Figure 8

$\beta$-Catenin acts as a mediator of MINDIN-induced changes on gene expression of MC3T3-E1 osteoblastic cells. MC3T3-E1 cells were stimulated with MINDIN ( $5 \mathrm{ng} / \mathrm{mL}$ ) for different time periods (A: 3 h, 6 h and 24 h; B and C: 24 h). $\beta$-Catenin was silenced in some experiments using specific siRNAs as described in materials and methods. (A) Detection of $\beta$-catenin was performed by indirect immunofluorescence and fluorescence microscopy. Images represent the results of three independent observations. DAPI was used to stain the nuclei. Nuclear (B) or total (C) cell protein fractions were isolated to evaluate nuclear catenin (B) or phospho- $\beta$-catenin and total $\beta$-catenin (C) protein expression by Western blot after MINDIN stimulation for 3-24 $\mathrm{h}$.

Representative autoradiograms are shown (top panels). $\alpha$-tubulin was used as loading control. (D, E, F and G) MC3T3 cells were stimulated with MINDIN $(5 \mathrm{ng} / \mathrm{mL})$ during $24 \mathrm{~h}$ in the presence of scrambled or $\beta$-catenin siRNAs. Total cell RNA was isolated to assess mRNA levels of $\beta$-catenin (D), RANK-L (E), OPG (F) and OPG/RANK-L ratio (G) by real-time PCR. Experimental values are mean \pm S.E.M. from three independent experiments. ${ }^{*} P<0.05$ versus control; a $P<0.05$ vs MINDIN-stimulated condition. A full colour version of this figure is available at https://doi. org/10.1530/ERC-20-0116. bone cell surfaces rather than to the extracellular matrix. Even though MINDIN significantly increased adhesion of prostate cancer cells to collagen, adhesion to osteoblastic or osteocytic cells was much higher. Previous studies showed that MINDIN serves as a ligand for integrins and that MINDIN-integrin interactions are critical for neutrophil, macrophage, and T lymphocyte recruitment in vivo (Jia et al. 2005, Li et al. 2006). It is thus possible that MINDIN binds to specific integrins in prostate cancer cells to enhance their adhesion to the bone extracellular matrix. Alternatively, binding of MINDIN to osteoblast and osteocyte integrins could trigger signals in these bone cells to facilitate adhesion of prostate cancer cells.
In this regard, a crosstalk between integrins, Fak and Src kinases has been related with cell adhesion (Huveneers \& Danen 2009). Our results showing inhibitory actions of Fak and Src kinase inhibitors on bone cell ability to promote TRAMP-C1 cell adhesion suggest an interplay between these kinases and integrins in prostate cancer cell homing to bone. Furthermore, mouse models of prostate cancer have shown that tumor cells home to areas in bone that have high numbers of osteoblasts in the endosteal niche (Shiozawa et al. 2011, Wang et al. 2014). The chemokine (C-X-C motif) receptor 4 (CXCR4)/chemokine ligand 12 (CXCL12) interaction is thought to be a key component in the homing and adhesion of tumor cells to 
A

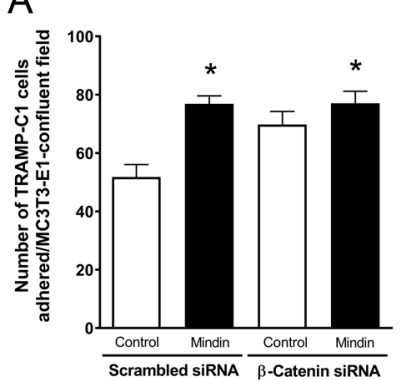

C

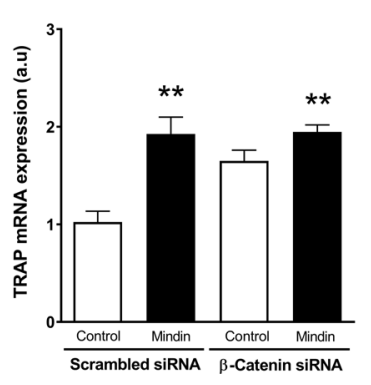

B
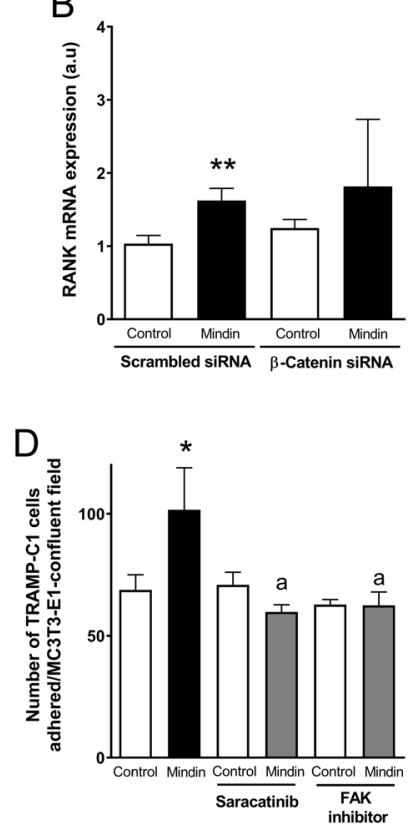

Figure 9

$\beta$-Catenin is not a mediator of MINDIN-induced adenocarcinoma TRAMP-C1 cell adhesion to osteoblastic-covered surfaces or osteoclastic differentiation. MC3T3-E1 (A) and RAW 264.7 (B and C) cells were transfected with scrambled control siRNA or $\beta$-catenin siRNA for $24 \mathrm{~h}$ and subsequently stimulated with PBS (control) or MINDIN peptide $(5 \mathrm{ng} / \mathrm{mL}$ ) for $24 \mathrm{~h}$. (A) Number of TRAMP-C1 cells labeled with calcein-AM and adhered to MC3T3-E1 cells was assessed. (B) RANK and (C) TRAP gene expression in RAW 264.7 cells was evaluated by real-time PCR. (D) Number of TRAMP-C1 cells labeled with calcein-AM and adhered to confluent MC3T3-E1-covered surfaces is shown. MC3T3-E1 cells were treated or not (control) with $1 \mu \mathrm{M}$ Fak inhibitor 14 or $1 \mu \mathrm{M}$ saracatinib (Src kinase inhibitor) for $24 \mathrm{~h}$ and stimulated with $5 \mathrm{ng} / \mathrm{mL}$ MINDIN for $24 \mathrm{~h}$. Experimental values are mean \pm S.E.M. from three independent experiments. ${ }^{*} P<0.05 ;{ }^{*} P<0.01$ vs control; a $P<0.05$ vs MINDINstimulated condition.

the metastatic niche in bone (Wang et al. 2014). CXCL12 is expressed by endosteal cells and a few layers of osteocytes underneath the endosteum (Myers et al. 2015). Therefore, MINDIN could promote an increase in CXCL12 expression in cells of the endosteum, in particular osteoblasts, to enhance CXCR4/CXCL12 interactions between tumor and osteoblastic cells. In this regard, adhesion of tumor cells to MINDIN-stimulated MC3T3-E1 osteoblastic cells was higher compared to MLO-Y4 osteocytes in our in vitro assays, suggesting that osteoblasts, being the most exposed cells at the endosteal niche, preferentially mediate prostate tumor cell binding to bone. Thus, MINDIN-dependent changes in bone microarchitecture, overexpression of bone factors, and enhanced tumor cell adhesion to bone surfaces, altogether, suggest that expression of MINDIN by primary prostate tumors induce a favorable niche for prostate tumor metastases.

MINDIN effects on bone are further supported by our in vitro observations showing the actions of this protein on osteoblast proliferation and differentiation, as well as modulation of different genes involved in bone formation and remodeling (e.g., Runx2, osteocalcin, osterix, OPG, RANK-L). Our conditioned medium experiments also corroborate these findings. As reported in the conditioned medium assays, MINDIN seems to be an important factor secreted by prostate cancer cells that modulates the behavior of bone cells. Prolonged exposure to MINDIN sustained overexpression of osteoblastic differentiation markers in osteoblastic cells but did not affect the OPG/RANK-L axis, suggesting that continuous stimulation with MINDIN promotes osteoblast differentiation but fails to further influence prolonged osteoblast-osteoclast communication. These results support our in vivo data showing increased Runx 2 expression but no significant changes in OPG and RANK-L levels in bones of prostate tumor-induced mice. Furthermore, osteocytes, the main regulators of RANK-L in bone (Nakashima et al. 2011), did not overexpress OPG or RANK-L after prolonged exposure to MINDIN, suggesting that osteogenic genes in osteoblastic cells are the main target of the bone formation actions of MINDIN. Interestingly, MINDIN also triggered osteoclast differentiation and activation after several days of stimulation. Stimulatory actions of MINDIN on both osteoblasts and osteoclasts in the absence of prolonged RANK-L and OPG overexpression could be responsible for uncoupled bone formation by osteoblasts and bone resorption by osteoclasts. In addition, the osteoclastic/ resorptive phenotype observed in our model may probably be caused by primary tumor secretion of RANK-L - which could potentially reach the bone microenvironment and participate as the main regulator of osteoclastic differentiation - rather than bone-secreted RANK-L.

There are no previous observations describing the signaling pathways triggered by MINDIN in bone cells. However, other members of the MINDIN family (spondin family) that share a similar thrombospondin domain, namely R-spondin, exhibit activation of the $\mathrm{Wnt} / \beta$-catenin pathway in association with osteogenesis (Friedman et al. 2009, Zhu et al. 2016). Wnt/ $\beta$-catenin activation also has been related to epithelial-mesenchymal transition (EMT), an essential process by which cells lose their epithelial characteristics and acquire mesenchymal features during tumor progression of human prostate cancer (Jiang et al. 2007). Therefore, MINDIN-dependent activation of the Wnt/ $\beta$-catenin pathway could be a central mechanism in prostate tumor progression and metastasis to bone. In this regard, our results showing Wnt11 downregulation 
in MINDIN-silenced prostate tumor cells suggest the putative role of Wnt signaling in prostate tumor EMT and in certain osteogenic actions of prostate cancer cells that express MINDIN.

The present data collectively show that overexpression of MINDIN in primary tumors promotes modifications of bone microarchitecture and gene expression in pre-metastatic areas in association with an increased adhesion potential to prostate tumor cells. In addition, pro-osteogenic effects were mediated by MINDIN-dependent actions on bone cells via a $\beta$-catenin signaling pathway. In conclusion, we propose that MINDIN favors the creation of pre-metastatic niches in bone by overexpressing bone remodeling factors and enhancing bone cell-dependent adhesion of prostate cancer cells.

\section{Supplementary materials}

This is linked to the online version of the paper at https://doi.org/10.1530/ ERC-20-0116.

\section{Declaration of interest}

The authors declare that there is no conflict of interest that could be perceived as prejudicing the impartiality of the research reported.

\section{Funding}

This work was supported by grants from the Instituto de Salud Carlos III (PI12/02390) and CEU San Pablo-Santander (USP-BS-PPC11/2012, USPBBS-APP-2/2016 and MERMERG-2 MCP19V10) and FEIOMM RESEARCH 2017 Scholarships.

\section{Author contribution statement}

Authors' roles: Study design: J A A and V A. Study conduct: $\vee A$. Data collection: I G R, L A C. Data analysis: J A A and V A. Data interpretation: J A A, A R G and V A. Drafting manuscript: J A A and V A. Revising manuscript content: J A A, P A F and $V A$. Approving final version of manuscript: J A A, I G R, L A C, A R G, P A F, and V A. V A takes responsibility for the integrity of the data analysis.

\section{Acknowledgements}

The authors thank CBMSO PROTEIN CHEMISTRY FACILITY that belongs to ProteoRed, PRB2-ISCIII, supported by grant PT13/0001" for the proteomic analysis. They also thank the Animal and Experimental Surgery Service of San Pablo CEU University for the support.

\section{References}

Akech J, Wixted JJ, Bedard K, Van Der Deen M, Hussain S, Guise TA Van Wijnen AJ, Stein JL, Languino LR, Altieri DC, et al. 2010 Runx2 association with progression of prostate cancer in patients: mechanisms mediating bone osteolysis and osteoblastic metastatic lesions. Oncogene 29 811-821. (https://doi.org/10.1038/ onc.2009.389)

Ardura JA, Gutiérrez Rojas I, Álvarez Carrión L, Friedman PA \& Alonso V 2018 Factors secreted by bone cells induce intracellular calcium accumulation and cyclic AMP and activation of ERK $1 / 2$ in prostate cancer cells; evaluation by fluorescence techniques in living cells. Revista de Osteoporosis y Metabolismo Mineral 10 131-138. (https://doi. org/10.4321/S1889-836X2018000400005)

Ardura JA, Gutiérrez-Rojas I, Álvarez-Carrión L, Rodríguez-Ramos MR, Pozuelo JM \& Alonso V 2019 The secreted matrix protein mindin increases prostate tumor progression and tumor-bone crosstalk via ERK 1/2 regulation. Carcinogenesis 40 828-839. (https://doi. org/10.1093/carcin/bgz105)

Baniwal SK, Khalid O, Gabet Y, Shah RR, Purcell DJ, Mav D, KohnGabet AE, Shi Y, Coetzee GA \& Frenkel B 2010 Runx2 transcriptome of prostate cancer cells: insights into invasiveness and bone metastasis. Molecular Cancer 9 258. (https://doi.org/10.1186/14764598-9-258)

Baron R \& Rawadi G 2007 Minireview: targeting the Wnt/ $\beta$-catenin pathway to regulate bone formation in the adult skeleton. Endocrinology 148 2635-2643. (https://doi.org/10.1210/en.20070270)

Chang H, Dong T, Ma X, Zhang T, Chen Z, Yang Z \& Zhang Y 2015 Spondin 1 promotes metastatic progression through Fak and Src dependent pathway in human osteosarcoma. Biochemical and Biophysical Research Communications 464 45-50. (https://doi. org/10.1016/j.bbrc.2015.05.092)

Costa-Silva B, Aiello NM, Ocean AJ, Singh S, Zhang H, Thakur BK, Becker A, Hoshino A, Mark MT, Molina H, et al. 2015 Pancreatic cancer exosomes initiate pre-metastatic niche formation in the liver. Nature Cell Biology 17 816-826. (https://doi.org/10.1038/ncb3169)

Cox TR, Rumney RMH, Schoof EM, Perryman L, Høye AM, Agrawal A, Bird D, Latif NA, Forrest H, Evans HR, et al. 2015 The hypoxic cancer secretome induces pre-metastatic bone lesions through lysyl oxidase. Nature 522 106-110. (https://doi.org/10.1038/nature14492)

Croucher PI, McDonald MM \& Martin TJ 2016 Bone metastasis: the importance of the neighbourhood. Nature Reviews: Cancer 16 373-386. (https://doi.org/10.1038/nrc.2016.44)

de Lau WBM, Snel B \& Clevers HC 2012 The R-spondin protein family. Genome Biology 13 242. (https://doi.org/10.1186/gb-2012-13-3-242)

Dempster DW, Compston JE, Drezner MK, Glorieux FH, Kanis JA, Malluche H, Meunier PJ, Ott SM, Recker RR \& Parfitt AM 2013 Standardized nomenclature, symbols, and units for bone histomorphometry: a 2012 update of the report of the ASBMR Histomorphometry Nomenclature Committee. Journal of Bone and Mineral Research 28 2-17. (https://doi.org/10.1002/jbmr.1805)

Ell B \& Kang Y 2012 SnapShot: bone metastasis. Cell 151 690.e1-690.e1. (https://doi.org/10.1016/j.cell.2012.10.005)

Friedman MS, Oyserman SM \& Hankenson KD 2009 Wnt11 promotes osteoblast maturation and mineralization through R-spondin 2. Journal of Biological Chemistry 284 14117-14125. (https://doi. org/10.1074/jbc.M808337200)

Gingrich JR, Barrios RJ, Morton RA, Boyce BF, DeMayo FJ, Finegold MJ, Angelopoulou R, Rosen JM \& Greenberg NM 1996 Metastatic prostate cancer in a transgenic mouse. Cancer Research $\mathbf{5 6}$ 4096-4102. (https://doi.org/10.1073/PNAS.92.8.3439)

Guise TA, Mohammad KS, Clines G, Stebbins EG, Wong DH, Higgins LS, Vessella R, Corey E, Padalecki S, Suva L, et al. 2006 Basic mechanisms responsible for osteolytic and osteoblastic bone metastases. Clinical Cancer Research 12 6213s-6216s. (https://doi. org/10.1158/1078-0432.CCR-06-1007)

Gupta GP \& Massagué J 2006 Cancer metastasis: building a framework. Cell 127 679-695. (https://doi.org/10.1016/j.cell.2006.11.001)

Huveneers S \& Danen EHJ 2009 Adhesion signaling - crosstalk between integrins, Src and Rho. Journal of Cell Science 122 1059-1069. (https://doi.org/10.1242/jcs.039446) https://erc bioscientifica com

https://doi.org/10.1530/ERC-20-0116 (c) 2020 Society for Endocrinology Published by Bioscientifica Ltd. Printed in Great Britain 
Jia W, Li H \& He YW 2005 The extracellular matrix protein mindin serves as an integrin ligand and is critical for inflammatory cell recruitment. Blood 106 3854-3859. (https://doi.org/10.1182/blood2005-04-1658)

Jiang YG, Luo Y, He DL, Li X, Zhang LL, Peng T, Li MC \& Lin YH 2007 Role of Wnt/ $\beta$-catenin signaling pathway in epithelial-mesenchymal transition of human prostate cancer induced by hypoxia-inducible factor-1 $\alpha$. International Journal of Urology 14 1034-1039. (https://doi. $\operatorname{org} / 10.1111 / \mathrm{j} .1442-2042.2007 .01866 . x)$

Jin JK, Dayyani F \& Gallick GE 2011 Steps in prostate cancer progression that lead to bone metastasis. International Journal of Cancer 128 2545-2561. (https://doi.org/10.1002/ijc.26024)

Kan C, Vargas G, Le Pape FL \& Clézardin P 2016 Cancer cell colonisation in the bone microenvironment. International Journal of Molecular Sciences 17 1674. (https://doi.org/10.3390/ijms17101674)

Kaplan RN, Riba RD, Zacharoulis S, Bramley AH, Vincent L, Costa C, MacDonald DD, Jin DK, Shido K, Kerns SA, et al. 2005 VEGFR1positive haematopoietic bone marrow progenitors initiate the premetastatic niche. Nature 438 820-827. (https://doi.org/10.1038/ nature04186)

Keller ET \& Brown J 2004 Prostate cancer bone metastases promote both osteolytic and osteoblastic activity. Journal of Cellular Biochemistry 91 718-729. (https://doi.org/10.1002/jcb.10662)

Kingsley LA, Fournier PGJ, Chirgwin JM \& Guise TA 2007 Molecular biology of bone metastasis. Molecular Cancer Therapeutics 6 2609-2617. (https://doi.org/10.1158/1535-7163.MCT-07-0234)

Koeneman KS, Yeung F \& Chung LW 1999 Osteomimetic properties of prostate cancer cells: a hypothesis supporting the predilection of prostate cancer metastasis and growth in the bone environment. Prostate 39 246-261. (https://doi.org/10.1002/(sici)10970045(19990601)39:4<246::aid-pros5>3.0.co;2-u)

Li H, Oliver T, Jia W \& He YW 2006 Efficient dendritic cell priming of T lymphocytes depends on the extracellular matrix protein mindin. EMBO Journal 25 4097-4107. (https://doi.org/10.1038/sj. emboj.7601289)

Li Y, Cao C, Jia W, Yu L, Mo M, Wang Q, Huang Y, Lim JM, Ishihara M, Wells L, et al. 2009 Structure of the F-spondin domain of mindin, an integrin ligand and pattern recognition molecule. EMBO Journal $\mathbf{2 8}$ 286-297. (https://doi.org/10.1038/emboj.2008.288)

Liu Y \& Cao X 2016 Characteristics and significance of the premetastatic niche. Cancer Cell 30 668-681. (https://doi.org/10.1016/j. ccell.2016.09.011)

Logothetis C, Morris MJ, Den R \& Coleman RE 2018 Current perspectives on bone metastases in castrate-resistant prostate cancer. Cancer Metastasis Reviews 37 189-196. (https://doi.org/10.1007/ s10555-017-9719-4)

Lucarelli G, Rutigliano M, Bettocchi C, Palazzo S, Vavallo A, Galleggiante V, Trabucco S, Di Clemente D, Selvaggi FP, Battaglia M, et al. 2013 Spondin-2, a secreted extracellular matrix protein, is a novel diagnostic biomarker for prostate cancer. Journal of Urology 190 2271-2277. (https://doi.org/10.1016/J.JURO.2013.05.004)

Mundy GR 2002 Metastasis to bone: causes, consequences and therapeutic opportunities. Nature Reviews: Cancer 2 584-593. (https:// doi.org/10.1038/nrc867)

Myers TJ, Longobardi L, Willcockson H, Temple JD, Tagliafierro L, Ye P, Li T, Esposito A, Moats-Staats BM \& Spagnoli A 2015 BMP2 regulation of CXCL12 cellular, temporal, and spatial expression is essential during fracture repair. Journal of Bone and Mineral Research 30 2014-2027. (https://doi.org/10.1002/jbmr.2548)

Nakashima T, Hayashi M, Fukunaga T, Kurata K, Oh-hora M, Feng JQ, Bonewald LF, Kodama T, Wutz A, Wagner EF, et al. 2011 Evidence for osteocyte regulation of bone homeostasis through RANKL expression. Nature Medicine 17 1231-1234. (https://doi.org/10.1038/ $\mathrm{nm} .2452)$

Nordstrand A, Ylitalo EB, Thysell E, Jernberg E, Crnalic S, Widmark A, Bergh A, Lerner UH \& Wikström P 2018 Bone cell activity in clinical prostate cancer bone metastasis and its inverse relation to tumor cell androgen receptor activity. International Journal of Molecular Sciences 19 1223. (https://doi.org/10.3390/ijms19041223)

Nuche-Berenguer B, Lozano D, Gutiérrez-Rojas I, Moreno P, Mariñoso ML, Esbrit P \& Villanueva-Peñacarrillo ML 2011 GLP-1 and exendin-4 can reverse hyperlipidic-related osteopenia. Journal of Endocrinology 209 203-210. (https://doi.org/10.1530/JOE-11-0015)

Ottewell PD 2016 The role of osteoblasts in bone metastasis. Journal of Bone Oncology 5 124-127. (https://doi.org/10.1016/j.jbo.2016.03.007)

Palmer GD, Attur MG, Yang Q, Liu J, Moon P, Beier F \& Abramson SB 2014 F-spondin deficient mice have a high bone mass phenotype. PLOS ONE 9 e98388. (https://doi.org/10.1371/journal. pone.0098388)

Peinado H, Alečković M, Lavotshkin S, Matei I, Costa-Silva B, MorenoBueno G, Hergueta-Redondo M, Williams C, García-Santos G, Ghajar CM, et al. 2012 Melanoma exosomes educate bone marrow progenitor cells toward a pro-metastatic phenotype through MET. Nature Medicine 18 883-891. (https://doi.org/10.1038/nm.2753)

Polyak K \& Hu M 2008 Molecular chacarterization of the tumor microenvironment in breast cancer. European Journal of Cancer 44 2760-2765. (https://doi.org/10.1016/j.ejca.2008.09.038.Molecular)

Qian X, Li C, Pang B, Xue M, Wang J \& Zhou J 2012 Spondin-2 (SPON2), a more prostate-cancer-specific diagnostic biomarker. PLoS ONE 7 e37225. (https://doi.org/10.1371/journal.pone.0037225)

Quail DF \& Joyce JA 2013 Microenvironmental regulation of tumor progression and metastasis. Nature Medicine 19 1423-1437. (https:// doi.org/10.1038/nm.3394)

Reithmeier A, Panizza E, Krumpel M, Orre LM, Branca RMM, Lehtiö J, Ek-Rylander B \& Andersson G 2017 Tartrate-resistant acid phosphatase (TRAP/ACP5) promotes metastasis-related properties via TGF $\beta 2 / T \beta R$ and CD44 in MDA-MB-231 breast cancer cells. BMC Cancer 17 650. (https://doi.org/10.1186/s12885-017-3616-7)

Roodman GD 2004 Mechanisms of bone metastasis. New England Journal of Medicine 350 1655-1664. (https://doi.org/10.1056/NEJMra030831)

Salamanna F, Borsari V, Brogini S, Giavaresi G, Parrilli A, Cepollaro S, Cadossi M, Martini L, Mazzotti A \& Fini M 2016 An in vitro 3D bone metastasis model by using a human bone tissue culture and human sex-related cancer cells. Oncotarget 7 76966-76983. (https:// doi.org/10.18632/oncotarget.12763)

Schmittgen TD \& Livak KJ 2008 Analyzing real-time PCR data by the comparative C(T) method. Nature Protocols 3 1101-1108. (https://doi. org/10.1038/nprot.2008.73)

Shiozawa Y, Pedersen EA, Havens AM, Jung Y, Mishra A, Joseph J, Kim JK, Patel LR, Ying C, Ziegler AM, et al. 2011 Human prostate cancer metastases target the hematopoietic stem cell niche to establish footholds in mouse bone marrow. Journal of Clinical Investigation 121 1298-1312. (https://doi.org/10.1172/JCI43414)

Somers KD, Brown RR, Holterman DA, Yousefieh N, Glass WF, Wright GL, Schellhammer PF, Qian J \& Ciavarra RP 2003 Orthotopic treatment model of prostate cancer and metastasis in the immunocompetent mouse: efficacy of flt3 ligand immunotherapy. International Journal of Cancer 107 773-780. (https://doi.org/10.1002/ ijc.11464)

Suva LJ, Washam C, Nicholas RW \& Griffin RJ 2011 Bone metastasis: mechanisms and therapeutic opportunities. Nature Reviews: Endocrinology 7 208-218. (https://doi.org/10.1038/nrendo.2010.227)

Touma M, Kang X, Gao F, Zhao Y, Cass AA, Biniwale R, Xiao X, Eghbali M, Coppola G, Reemtsen B, et al. 2017 Wnt11 regulates cardiac chamber development and disease during perinatal maturation. JCI Insight 2 e94904. (https://doi.org/10.1172/jci. insight.94904)

Wang N, Docherty FE, Brown HK, Reeves KJ, Fowles AC, Ottewell PD, Dear TN, Holen I, Croucher PI \& Eaton CL 2014 Prostate cancer cells preferentially home to osteoblast-rich areas in the early stages of bone metastasis: evidence from in vivo models. Journal of Bone and Mineral Research 29 2688-2696. (https://doi.org/10.1002/jbmr.2300) https://erc bioscientifica com

https://doi.org/10.1530/ERC-20-0116 (c) 2020 Society for Endocrinology Published by Bioscientifica Ltd. Printed in Great Britain 
Weilbaecher KN, Guise TA \& McCauley LK 2011 Cancer to bone: a fatal attraction. Nature Reviews: Cancer 11 411-425. (https://doi. org/10.1038/nrc3055)

Zayzafoon M, Abdulkadir SA \& McDonald JM 2004 Notch signaling and ERK activation are important for the osteomimetic properties of prostate cancer bone metastatic cell lines. Journal of Biological Chemistry 279 3662-3670. (https://doi.org/10.1074/jbc. M308158200)
Zhu C, Zheng XF, Yang YH, Li B, Wang YR, Jiang SD \& Jiang LS 2016 LGR4 acts as a key receptor for R-spondin 2 to promote osteogenesis through Wnt signaling pathway. Cellular Signalling 28 989-1000. (https://doi.org/10.1016/J.CELLSIG.2016.04.010)

Zhu BP, Guo ZQ, Lin L \& Liu Q 2017 Serum BSP, PSADT, and Spondin-2 levels in prostate cancer and the diagnostic significance of their ROC curves in bone metastasis. European Review for Medical and Pharmacological Sciences 21 61-67.

Received in final form 3 April 2020

Accepted 29 April 2020

Accepted Manuscript published online 1 May 2020
(C) 2020 Society for Endocrinology Published by Bioscientifica Ltd. Printed in Great Britain 